\title{
business Knowledge Management for Business Growth
}

R E V E $\mathbf{W} *$ *d. Khashrul Alam ', Sarif Mohammad Khan ${ }^{2}$

a journal of business

administration discipline

Abstract

The study aims to explore the current status of knowledge management by exploring the meaning of knowledge, knowledge management, knowledge management system (KMS), benefits of KMS and the ways to extract the benefits. Knowledge management is concerned with the exploitation and development of the knowledge assets of an organization with a view to furthering the organization's objectives. The knowledge to be managed includes both explicit, documented knowledge, tacit and subjective knowledge. Knowledge management can help to take decision in a congenial atmosphere, increases the competences of the organization and make the company more and more agile. That means company can prosper in rapidly changing, continually fragmenting global markets for high quality, high performance, customer configured products and services. Knowledge process planning, knowledge sharing culture and knowledge stewardship are the ways by which firms can extract those benefits.

Key Words: Tacit and explicit knowledge, Knowledge steward ship, Knowledge management system, and Business growth

\section{Introduction}

A wealth of knowledge rather than a wealth of tangible assets is key determining factor for national competitiveness and quality of life (Rooney and Mandeville, 1998). This is also true in business organization. Business can be of any situation like a business in emerging industry, in turbulent high velocity markets, in maturing industry, in stagnant or declining industry, in leadership position or in crisis ridden situation (Thompson \& Strickland, 2004). To cope up with any of those situation, firm's need to take so many actions like innovate ideas, build strong relations with supplier, mange customers promptly and accurately, create a strong value chain and so on. In addition to this, business needs faster communication with all stakeholders, proactive marketing and better customer focuses with a view to increase sales and decrease cost. Knowledge management practice can help to implement those activities effectively.

\section{Methodology}

To explore the present status of knowledge management, this paper address the meaning and development of knowledge management and finds the way of how business derive competitive benefits through introducing knowledge management. To meet the objective mainly secondary sources of data have been analyzed.

\section{Meaning and Development of Knowledge Management}

Knowledge is a fluid mix of framed experience, values, contextual information, and expert insight that provides a framework for evaluating and incorporating new experience and information (Davenport et al, 1998). However, according to Lang, knowledge is both produced

*Corresponding Author

'Md. Khashrul Alam, Assistant Professor, Business Administration Discipline, Khula University, Khulna-9208. Bangladesh

2Sarif Mohammad Khan, Assistant Professor, Business Administration Discipline, Khulna University, Khulna-9208 Bangladesh 
and held collectively rather than individually, in knit group or communities of practice (Lang, 2001). Knowledge could be broadly grouped into individual knowledge and organizational knowledge. Individual knowledge is knowledge that resides in an individual mind. Organizational knowledge, on the other hand, is knowledge that is formed through interactions among technologies, techniques and people (Yahya and Goh, 2002). The pattern and form of interactions depends on organization's history and culture (Bhatt, 2001). Organizational knowledge could be further classified into explicit and tacit knowledge (Nonka, 1991). Explicit knowledge can be documented and shared through IT; it is structured, fixed content, externalized and conscious. Tacit knowledge is the exact opposite to explicit knowledge. It is located underneath the surface of the iceberg and it is hard to be codified and documented. This is because tacit knowledge resides in the human mind, behavior and perception; it is personal, cognitive, and context- sensitive in nature. Examples of tacit knowledge are intuitions. hunches, insights, beliefs, and values (Yahya and Goh, 2002)

\section{Knowledge Management}

Knowledge management is concerned with the exploitation and development of the knowledge assets of an organization with a view to furthering the organization's objectives. The knowledge to be managed includes both explicit, documented knowledge, tacit and subjective knowledge. Management entails all of those process associated with the identification, sharing, and creation of knowledge. Organizations that succeed in knowledge management are likely to view knowledge as an asset and to develop organizational norms and values, which support the creation, and sharing of knowledge (Davenport et al., 1998). According to Galgan knowledge management process includes

- Generating new knowledge

- Accessing knowledge from external sources

- Representing knowledge in documents, databases, software and so forth.

- Embedding knowledge in process, products, or services.

- Transferring existing knowledge around an organization.

- Using accessible knowledge in decision-making.

- Facilitating knowledge growth through culture and incentives.

- Measuring the value of knowledge assets and the impact of knowledge management.

Knowledge management is still a fairly new set of policies and practices, which still mean many things to many people. There are several schools who have defined knowledge management in different ways (Neef, 1999) .One school, the high touch group, has always believed that knowledge management should be primarily concerned with organizational cultures and encouraging employees to share knowledge internally and develop more collaborative working relationship. A second school, the high tech, group has seen knowledge management primarily as a function of new communication technologies, concerned with how companies set up an internal electronic network to allow free flow of communication among employees from all locations around the company. 


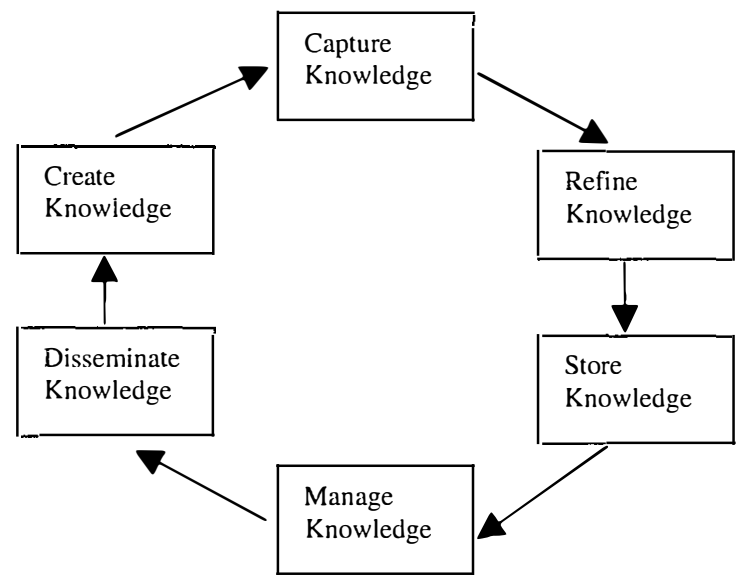

Figure: The Knowledge Management Cycle

Knowledge management refers to the set of business processes developed in an organization to create, store, transfer, and apply knowledge. Knowledge management is, in this sense, an enabler of organizational learning. Knowledge management increases the ability of the organization to learn from its environment and to incorporate knowledge into its business process. The following diagram shows knowledge management concept (Laudon and Laudon, 2006).

Data information acquisition $\rightarrow$ acquire $\rightarrow$ store $\rightarrow$ disseminates $\rightarrow$ apply

Knowledge Management System: The goal of knowledge management system is to help knowledge workers create,

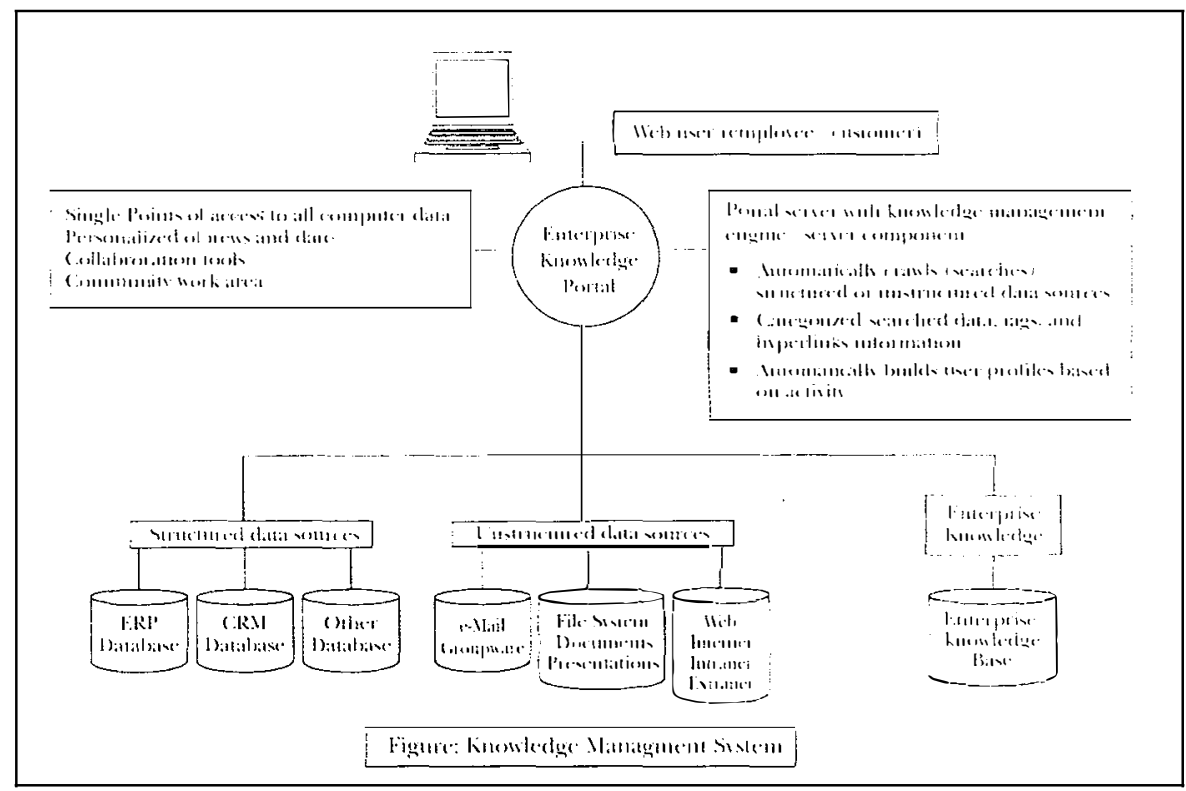


organize and make available important business knowledge, wherever and whenever it's needed in organization. This includes processes, procedures, patents, reference works, formulas "best practices". forecasts, and fixes. Internet and intranet websites, groupware, data mining, knowledge bases and online discussion groups are some of the key technologies that may be used by a KMS. Figure above shows the typical example of Knowledge management portal (Brien, 2004).

The major commercial knowledge management system vendors are integrating their content and document management capabilities with powerful portal and collaboration technologies. It provides access to external sources of information, such as news feeds and research, as well as to internal knowledge resources along with capabilities for e-mail, chat/ discussion groups, and video conferencing. It also provides especially for knowledge workers the specialized tools they need, such as power full graphics, analytical tools, and communication and document management tools. Artificial intelligence and database technologies provide a number of intelligent techniques that organization can use to capture individual and collective knowledge and to extend their knowledge base. Expert system, case based reasoning, and fuzzy logic are used for capturing tacit knowledge. Neural networks and data mining are used for knowledge discovery. They can discover underlying patterns, categories, and behaviors in large data sets that could not be discovered by manager alone or simply through experience (Laudon and laudon, 2006).

\section{Implications of Knowledge Management System}

Knowledge management can be used to generate critıcism free decision, developing competences and increase the agility of the firm and improve problem-solving skills.

Generate Criticism Free Decision: The knowledge management practice ensures every body's participation in taking decision. Here knowledge is generated through everybody's involvement. In a knowledge management system all employees are connected to groupware or collaborative software. This enables every employee to contribute regarding any ideas. Based on those contributions organization can reach in a better decision. Moreover, organization can get help of the knowledge database, which also helps to take unique decision.

Developing Competencies: A competence is the product of learning and experience and represents real proficiency in performing an internal activity. Company competencies are normally bundles of skills; know how, resources and technologies. Examples are skills in merchandising and product display, the ability to select attractive locations for outlets, skills in working with customers on new applications and uses of the product (Thompson and Strickland, 2004). Skills both tacit and explicit can be explored through knowledge management system and disseminated all through the organization. At the same time explored skills, experiences, know how's can be integrated to firm's product or service.

Help to become Agile Company: Agility in business performance is the ability of a company to prosper in rapidly changing, continually fragmenting global markets for high quality, high performance, customer configured products and services. An agile company can make profit in markets with broad products ranges and short model lifetimes, and can produce orders in arbitrary lot sizes (Brien, 2004). Knowledge management utilizes all sort of knowledge like tacit, explicit, documented and subjective knowledge. As a result it becomes easier to fix up 
strategies to cope up with the changes, ensures high performance and enables the company to offer customized products or services.

Improves Problem-Solving Skill: Knowledge management system links the employees of the organization through intranet, extranet, groupware software and so many information technologies. Therefore problem solving becomes faster, easier, and less error pone.

Ways to get the Benefits: According to Dale Neef, benefits can be derived through knowledge process planning, encouraging knowledge sharing culture and knowledge stewardship.

Knowledge Process Planning: It entails establishing a formal knowledge process in which the company - usually sponsored by a central knowledge management group- helps documents or work processes (marketing, corporate planning, etc.) identify what knowledge is needed, by whom, and when. This knowledge mapping process entails developing a directory of knowledge resources or a knowledge yellow pages" for the firm which identifies what information and knowledge is available throughout the company. As for example Chevron designed a knowledge resource "road map" which not only identified who had what skills with in the company, but helped to establish a series of human knowledge networks which meet four to six times a year. keeping in touch in between with an electronic database.

Encouraging a Knowledge Sharing Culture: Business should ensure that, knowledge worker should share what they know with their colleagues. Creating a knowledge sharing culture is certainly not some thing that can be done simply or easily. Years of command and control management and fear in the work place cannot readily be overcome with encouraging speeches from the chairman exulting the need for employees to change their behavior, work together, and share ideas. Some of the most effective techniques to encourage knowledge sharing are actually the most basic. The wide spread development of internal knowledge net works, or communities of practice, where practitioners with similar interests and knowledge from around the firm meet in dedicated groups to discuss leading practices and lessons learned (then continue to communicate by way of interactive discussion databases), has helped many firms to establish a culture that encourages the sharing of productivity improvements techniques.

Knowledge Stewardship: The lack of any organization's strategy concerning the method for capturing, organizing, maintaining, formatting, and distributing information has too often resulted in a daunting "information jungle" which seemed to overwhelm employees and discourage common database use. In order to mange the problems organization needs to employ -Chief knowledge officer- whose duty is not only to manage databases but also to act as the coordinating intermediary between those who provide the systems and those who use them (Neef,1999).

\section{Conclusion}

Business should determine what, when and how knowledge is required. If it is diagnosed properly, it is easy to be agile, and competitive. Especially firm should focus more on knowledge process planning and knowledge share culture. In addition to these, the role of chief knowledge officer is very important. Success largely depends on the quality and capability of chief knowledge officer. In order to be successful he should know the techniques to generate, organize, maintain, format, and to distribute knowledge, where and when needed. 


\section{References}

Thompson, A A and Strickland, A J (2004). "Strategic Management". Thirteenth Edition, New Delhi: Tata McGraw Hill Publishing Company Ltd, pp. 120-125

Brien, J A (2004). "Competing with Information Technology", Management Information System. Fifth Edition. New Delhi: Tata McGraw Hill, pp. 60-65, 279.

Yahya, S and Goh, W K (2002). "Managing Human Resources Toward Achieving Knowledge Management". Journal of Knowledge Management, Vol. 6, No. 5, pp. 457-468

Bhat, G D (2001). "Knowledge Management in Organizations: Examining the Interaction between Technologies, Techniques and People". Joumal of Knowledge Management, Vol. 5. No. 1, pp. 68-75.

Davenport, D; Long, D W and Beers, M C (1998). "Successful Knowledge Management Projects". Sloan Management Review. Vol. 39. No. 2, pp. 43-58.

Lang, J C (2001). "Managerial Concerns in Knowledge Management". Journal of Knowledge Management, Vol. 5. No. 1, pp. 43-57.

Nonaka, I (1991). "The Knowledge Creating Company". Harvard Business Review, Vol. 34, No. 6. pp. 96-104

Martensson, M (2000). "A Critical Review of Knowledge Management as a Management Tool”. Journal of Knowledge Management, Vol. 4, No. 3, pp. 204-216

Rooney, D and Mandeville, T (1998). "The Knowing Nation: A Framework for Public Policy in a Postindustrial Knowledge Economy". Prometheus, Vol. 16, No. 4, pp. 455-469.

Neef, D (1999). "So Why Knowledge Management and Why Now: A little Knowledge is a Dangerous Thing: Understanding Our Global Knowledge Economy", Melbourne: Butterworth Heinemann. pp. 113 142

Laudon, K C and Laudon, J P (2006). "Managing Knowledge in the Digital Firm". Management Information System, $9^{\text {th }}$ Edition, Pearson Prentice Hall, New Jersey: PP. 414-448.

Galgan, P (1997). "Smart Companies Knowledge Management". Training and Development, Vol. 51, No. 12, pp. $20-25$. www.emeraldinsight.com/1367-3270.htm 